\title{
Institucionalização das iniciativas socioambientais das organizações: interfaces entre a teoria do desenvolvimento social de Habermas e o isomorfismo da teoria institucional
}

\author{
Institutionalization of socioenvironmental initiatives of organizations: interfaces between \\ Habermas' social development theory and the isomorphism of the institutional theory
}

\author{
Martinho Luis Kelm ${ }^{1}$ \\ Cíntia Lisiane da Silva Renz ${ }^{2}$ \\ Sérgio Luís Allebrandt ${ }^{3}$ \\ Jorge Oneide Sausen ${ }^{4}$
}

\begin{abstract}
Resumo
Este artigo estabelece uma discussão a partir da premissa de que a institucionalização envolve processos por meio dos quais valores sociais (práticas, crenças e obrigações) assumem o status de regras de pensamento e de ação social. Busca, assim, indicar como uma sociedade viabiliza a materialização de novos padrões de racionalidade, de modo que estes passem a interferir nas concepções de realidade de seus sujeitos. O estudo apresenta um modelo de análise sistêmico da responsabilidade social corporativa, integrando os conceitos da lógica do desenvolvimento social, proposta por Jürgen Habermas, e os processos de isomorfismo observados nas organizações e oriundos da teoria institucional. Com o intuito de fornecer um modelo de análise teórico-empírica do tema, as iniciativas socioambientais são justificadas, inicialmente, pelo seu papel como fator de diferenciação ou como estabelecedor da reputação da organização e de seus produtos e serviços. Na sequência, observa-se um processo de normatização, quando é definido um novo padrão mínimo de atuação das organizações e, porque não dizer, de maturidade social, reiniciando nesse ponto uma nova busca de diferenciais competitivos e avanços sociais. Esse enfoque de investigação da atuação das empresas na arena socioambiental rompe com a perspectiva ingênua e voluntarista de que a emergência dessas iniciativas ocorra conforme diferentes níveis de conscientização do meio empresarial.
\end{abstract}

Palavras-chave: Teoria institucional. Isomorfismo. Iniciativas socioambientais. Desenvolvimento social.

Artigo submetido em 14 de junho de 2013 e aceito para publicação em 19 de maio de 2014

DOI: http://dx.doi.org/10.1590/1679-39519097

${ }^{1}$ Doutor em Engenharia da Produção pelo PPGEP/UFSC; Mestre em Administração pelo PPGA/UFRGS; Professor do PPGDES/UNIJUÍ. Endereço: Programa de Pós-Graduação em Desenvolvimento da UNIJUÍ. Cx. Postal 560, Rua do Comércio, 3000, Bairro Universitário, CEP 98700-000, ljuí - RS, Brasil. E-mail: martinho@unijui.edu.br

${ }^{2}$ Mestre em Desenvolvimento pelo PPGDES/UNIJUÍ; Professora do IFRS - Campus Osório. Endereço: Instituto Federal de Educação, Ciência e Tecnologia do Rio Grande do Sul, IFRS - Campus Osório. Av. Santos Dumont, 2127, Albatroz, CEP 95520-000, Osório - RS, Brasil. E-mail: cintiarenz@yahoo.com.br

${ }^{3}$ Doutor em Desenvolvimento Regional pelo PPGDR/UNISC; Mestre em Gestão Empresarial pela EBAPE/FGV. Professor do PPGDES/UNIJUÍ. Endereço: Programa de Pós-Graduação em Desenvolvimento da UNIJUÍ. Cx. Postal 560, Rua do Comércio, 3000 , Bairro Universitário, CEP 98700-000, ljuí - RS, Brasil. E-mail: allebr@unijui.edu.br

${ }^{4}$ Doutor em Engenharia da Produção pelo PPGEP/UFSC; Pós-Doutor em Administração pela EBAPE/FGV; Professor do PPGDES/UNIJUÍ. Endereço: Programa de Pós-Graduação em Desenvolvimento da UNIJUÍ. Cx. Postal 560, Rua do Comércio, 3000, Bairro Universitário, CEP 98700-000, ljuí - RS, Brasil. E-mail: josausen@unijui.edu.br 


\begin{abstract}
This article establishes a discussion from the premise that institutionalization involves processes by which social values (practices, beliefs, and obligations) take the status of rules of thought and social action. Thus, it aims to point out how a society enables the embodiment of new rationality standards, so that they start interfering with the reality conceptions of their subjects. The study introduces a model for systemic analysis of corporate social responsibility, integrating concepts of the social development rationale, as proposed by Jürgen Habermas, and the processes of isomorphism observed in organizations and derived from the institutional theory. In order to provide a model for theoretical and empirical analysis of the subject, socioenvironmental initiatives are initially justified by their role as a differentiation factor or as establisher of the reputation of the organization and its products and services. Next, a normalization process is observed, when a new minimum performance standard is set for organizations, as well as, why not say it, social maturity, restarting at this point a new search for competitive differentials and social advances. This focus of investigation of companies' work in the socioenvironmental arena breaks with the naive and proactive perspective that the emergence of these initiatives occurs according to different levels of corporate environment awareness.
\end{abstract}

Keywords: Institutional theory. Isomorphism. Socioenvironmental initiatives. Social development.

\title{
Introdução
}

Como é possível analisar os vínculos existentes na formação dos juízos morais dos indivíduos de uma determinada sociedade diante das transformações dessa sociedade? Como uma sociedade viabiliza a materialização de novos padrões de racionalidade, de modo que estes passem a interferir nas concepções de realidade de seus sujeitos?

A problematização dessas questões é útil para uma análise estrutural de um dos grandes temas recorrentes nos estudos organizacionais contemporâneos, qual seja: a possibilidade de responsabilizar socialmente organizações quanto à tomada de posição (ou não) diante de questões socioambientais que, para muitas delas, podem inclusive fugir do foco de seu negócio. Nesse contexto, convive-se com um verdadeiro frenesi organizacional que exige um grau de consciência de cada entidade, de modo que estas implementem ações concretas de minimização das mazelas sociais ou dos riscos ambientais. As organizações, de um modo geral, seriam responsáveis pela sua solução.

Não obstante a nobreza desses propósitos, é necessário chamar atenção para o próprio conceito de "responsabilidade" e também para os riscos de se implementar ações que, apesar de seus elevados propósitos, fujam dos objetivos das entidades. Isso deve ser considerado, principalmente, quando estas reúnem indivíduos com funções e interesses variados e que, além disso, tenham percepções bastante diferentes - quando não, até divergentes - do seu papel na sociedade. Em muitos casos, o único denominador comum entre esses agentes é a consecução dos objetivos predefinidos dessas organizações, objetivos cujo não cumprimento ensejará os denominados conflitos de agência.

Com relação ao conceito de responsabilidade, este pode ter um sentido pretérito de "imputabilidade" que significa a atribuição de uma ação a um agente, considerado este seu causador. A responsabilidade pode também ser analisada tendo como premissa a liberdade, especificamente vinculada ao conceito de liberdade limitada. Nesse sentido, sua compreensão é a de que, na hipótese de uma pessoa ser assim adjetivada, ela "inclui nos motivos de seu comportamento a previsão dos possíveis efeitos dele decorrentes" (ABBAGNANO, 2000, p. 855). Assim, utilizar-se-á nessa discussão um misto desses conceitos, entendendose que a responsabilidade abarca um compromisso acordado entre as partes, ou legitimamente determinado, com relação à geração de um resultado ou comportamento.

Segundo essa concepção, a responsabilidade organizacional deve, necessariamente, originar-se de um processo legalmente estabelecido ou socialmente legitimado. Essa assertiva nos leva ao propósito deste 
artigo, que é discutir um processo de análise da dinâmica social que viabiliza a materialização de novos padrões de racionalidade, de modo que estes passem a interferir nas concepções de realidade de seus sujeitos e, consequentemente, determinem a institucionalização de estruturas de racionalidade nas organizações. Essa dinâmica possibilitaria que as ações abarcadas no que hoje se denomina responsabilidade social pudessem ser explicadas por essas novas estruturas de racionalidade institucionalizadas na sociedade e em suas organizações. Para tanto, será utilizada, inicialmente, uma estrutura conceitual da teoria institucional, sendo o tema problematizado com base no que Habermas (1989) discute sobre a evolução social, de modo a permitir o estabelecimento de alguns possíveis vínculos dessas abordagens com o tema da responsabilidade social corporativa. Por fim, apresenta-se um construto teórico que procura explicar como acontece o processo de institucionalização das ações sociais na lógica do desenvolvimento.

\section{A Evolução Social e a Valorização da Esfera Pública em Habermas}

Para os objetivos deste artigo, é importante fundamentar a dinâmica pela qual a sociedade constitui novos padrões de racionalidade que possam ser institucionalizados nas diversas esferas da sociedade, entre as quais suas organizações.

Com esse propósito será aqui utilizada como referência à teoria da evolução social de Habermas, que na verdade é uma aplicação de sua teoria da racionalidade, ao considerar que, antes da evolução social propriamente dita, é necessário que ocorra uma evolução das estruturas de consciência coletiva traduzidas em fases da moralidade ${ }^{5}$ e da lei; elementos que darão substância ao processo de evolução real da sociedade. Habermas considera o conceito de "lógica" em oposição à "dinâmica" do desenvolvimento e enfatiza o papel das "relações" de produção como determinantes, ao invés das "forças" de produção, conforme estabelece o materialismo histórico.

Segundo Habermas (1989), há uma transformação estrutural do mundo-da-vida devido à elevação da complexidade sistêmica, a qual tem uma dimensão de reprodução simbólica e, outra, posterior e condicionada à primeira, de reprodução material. Na reprodução simbólica, ocorre a alteração dos elementos normativos do mundo-da-vida de um dado nível de organização da sociedade, de modo que estruturas morais e legais se modificam, criando um cenário ideologicamente viável para novas relações sociais. Segundo Habermas:

em última análise, as formações sociais são diferenciadas pelos núcleos institucionais que definem a base da sociedade. Essas instituições básicas formam uma série de inovações evolutivas que só podem surgir se o mundo-da-vida for suficientemente racionalizado, sobretudo somente se o direito e a moralidade tiverem alcançado um estágio de desenvolvimento correspondente. (Idem, 1989, p. 173)

Dessa forma, Habermas considera que ocorre uma evolução das estruturas de mundos-da-vida históricos, de modo que a sociedade vai incorporando elementos morais que avançam pelos estágios pré-convencional, convencional e, hipoteticamente, pós-convencional propostos por Kohlberg (1958). Nessa evolução, o aumento da complexidade sistêmica somente pode ocorrer pela adoção de um novo mecanismo sistêmico que deve ser institucionalizado na forma de estruturas morais e legais, viabilizando, na sequência, as

\footnotetext{
${ }^{5}$ Habermas (1989) explora as fases da moralidade a partir dos estudos de Kohlberg (1958), que introduz uma escala de seis estágios que compreendem a seguinte ordem: (i) orientação para a punição e a obediência, (ii) orientação ingênua e egoísta, (iii) orientação para o ideal do bom menino, (iv) orientação para a preservação da autoridade e da ordem social, (v) orientação legalista-contratual e (vi) orientação por princípios. Mais tarde se subdividirá os seis estágios em três níveis, a saber: pré-convencional, convencional e pósconvencional.
} 
transformações materiais intencionais promovidas pelos diversos atores sociais. É a partir desse novo estágio do subconsciente coletivo que se estabelecerão as novas relações e as novas conformações visíveis das estruturas normativas da sociedade.

Segundo a análise de Habermas, efetuada por Aragão (1992, p. 77), somente "depois da institucionalização de uma nova forma de integração social é que pode haver aumento da complexidade sistêmica, ou seja, evolução do nível das forças produtivas". Habermas considera que é na capacidade de aprendizagem de indivíduos, grupos ou organizações na busca do equacionamento de problemas sistêmicos que está a origem da evolução social, visto que essas soluções, ao serem partilhadas, constituem um novo estoque de conhecimento social que passa a referenciar comunicativamente novas ações e relações. Constituem novas instituições, que são a materialização de padrões de racionalidade compartilhados. Em um paralelo biológico, considera-se que o desenvolvimento evolutivo da espécie (filogênese) é uma decorrência do desenvolvimento dos indivíduos (ontogênese) que, por sua vez, pode ser analisado pelo desenvolvimento da capacidade de conhecimento, da capacidade linguística e da capacidade interativa destes.

A partir desse ponto, podemos avançar na análise da emergência da responsabilidade social corporativa no contexto teórico empírico e cotidiano das relações indivíduo/sociedade e sociedade/empresa, como decorrente de um processo de transformação simbólica do mundo-da-vida na sociedade contemporânea. Para tanto, é necessário compreender porque essa discussão se retira do meio legal-normativo para povoar o meio social-normativo.

No entendimento dos autores deste artigo, essa transformação simbólica da consciência coletiva (que amplia as responsabilidades das organizações com elementos que historicamente não lhes eram exigidos) não se dá apenas nas premissas e valores que conformam a sociedade em cada estágio de desenvolvimento. Essa transformação também se verifica na modificação do poder de influência de cada esfera social na formação do subconsciente coletivo em um determinado período histórico. Nesse sentido, Vieira (2001), ancorado na proposição de Thomas Janoski, divide a sociedade em quatro esferas interativas: a esfera privada, constituída pela vida familiar, amizades e dispositivos de propriedade pessoal; a esfera estatal, constituída do Legislativo, Executivo e do Judiciário; a esfera do mercado, constituída por organizações privadas (e algumas públicas como a Petrobras, por exemplo) voltadas à geração de riqueza e lucro, além de entidades sindicais e profissionais; e, finalmente, a esfera pública ampliada (não estatal), constituída por partidos políticos, grupos de interesse, associações de bem-estar social, movimentos sociais e grupos religiosos.

Neste macroespaço, percebe-se atualmente uma relativização do papel da esfera estatal pela evolução dos direitos $^{6}$ que normatizaram a ação do Estado, pela fragilização econômica de iniciativas do denominado welfare state e, ainda, pela ascensão dos movimentos neoliberais na onda dos processos de globalização. Embora possa parecer paradoxal, igualmente na esfera do mercado, a sociedade clama por mudanças, o que é cada vez mais evidente pela incapacidade do mercado se autorregular. ${ }^{7}$

Nesse quadro, os movimentos que densificam um novo conjunto de compromissos organizacionais parecem originar-se de modo cada vez mais contundente da esfera pública não estatal, que assume grande relevância na disputa entre princípios divergentes de organização da sociabilidade. Essa esfera pública não necessita

\footnotetext{
${ }^{6}$ Esse processo histórico de reconversão de uma sociedade pautada por deveres para uma sociedade orientada por direitos é muito bem descrita por Bobbio (1992) que demonstra que os direitos do homem passaram por três fases: (1) afirmam-se os direitos de liberdade; isto é, todos aqueles direitos que tendem a limitar o poder do Estado e a reservar para o indivíduo, ou para os grupos particulares, uma esfera de liberdade em relação ao Estado; (2) num segundo momento, foram promulgados os direitos políticos, entre os quais - concebendo a liberdade não apenas negativamente, como não impedimento, mas positivamente, como autonomia - a liberdade no Estado; (3) finalmente, foram proclamados os direitos sociais, exigências de novos valores, como do bem-estar e da igualdade não apenas formal, e que poderiam se chamar liberdade por meio do Estado.

${ }^{7}$ Um exemplo dessa incapacidade do mercado foi a crise financeira global decorrente do subprime americano. A lógica microeconômica de maximização de riqueza dos indivíduos sobrepôs-se à própria sobrevivência do conjunto de organizações que pela falta de instrumentos de regulação colocaram em cheque o sistema como um todo.
} 
retirar espaço das demais esferas para garantir sua ação. Esse espaço lhe é concedido pelas demais esferas que, muitas vezes, aguardam, reagem ou induzem movimentos normativos e de legitimação. Um exemplo disso é o movimento dos direitos do consumidor ou de qualidade e controle de processos certificados (operacionalizado pelas diversas normas de certificações). Nesse exemplo específico, é conveniente e imprescindível que esse processo de certificação de "organizações do mercado" ocorra fora da "esfera do mercado", para garantir sua maior legitimidade.

Ainda na esfera pública não estatal, as entidades da sociedade civil têm a possibilidade de atuar e modificar um segundo elemento de "colonização" mencionado por Habermas, que é o poder, por intermédio da política. Segundo Vieira (2001, p. 73),

os processos de reprodução sociocultural se convertem em forma política no espaço público. As associações civis absorvem iniciativas sociais difusas, encaminhando-as ao espaço público para o embate político. As associações e os movimentos sociais ampliam o espectro do político, incorporando novos temas na agenda política, desempenhando, assim, papel fundamental na construção do espaço público.

Essas organizações da sociedade civil têm a possibilidade de interferir tanto "no" como "por meio do" Estado e mercado, definindo e institucionalizando procedimentos e padrões materiais de racionalidade que constituirão limites para atuação das entidades que compõem a sociedade. Podem ser mencionadas ainda as diversas organizações não governamentais (ONGs) que também constituem um novo recorte social.

Ou seja, do mesmo modo como se vivenciaram períodos históricos quando a cultura e a identidade da sociedade foram fortemente influenciadas a partir da esfera estatal, depois pela esfera do mercado, temos atualmente não uma preponderância, mas uma maior influência da esfera pública não estatal, na tentativa de promover modificações sistêmicas no mundo-da-vida, considerando a lógica de desenvolvimento de Habermas. Essa base conceitual será retomada na terceira seção deste artigo, buscando-se demonstrar como um movimento tipicamente estratégico organizacional (que é o uso competitivo de ações de responsabilidade social) poderia estar também contribuindo para a modificação de valores do subconsciente social com repercussões de caráter socionormativo.

Antes, no entanto, é necessário discutir esse tema na dimensão organizacional, fundamentando conceitualmente o modo como ocorrem os processos de homogeneização de abordagens competitivas por meio dos processos de isomorfismos discutidos pela teoria institucional. É justamente o resultado desse processo de homogeneização organizacional que poderá constituir-se em elemento de transformação sistêmica do mundo-da-vida e, na sequência, repercutir normativamente.

\section{O Institucionalismo no Processo de Percepção da Realidade}

A teoria institucional tem suscitado um conjunto de debates nas últimas décadas, abrangendo um espectro bastante amplo do conhecimento. Seja em uma perspectiva social e política mais abrangente (BERGER e LUCKMANN, 2008; HABERMAS, 1989, HALL e TAYLOR, 2003), seja também em uma perspectiva específica, como a teoria organizacional (DIMAGGIO e POWELL, 2005). Esses autores têm procurado demonstrar não apenas a influência de elementos institucionalizados no cotidiano das organizações e da sociedade, mas também o modo como estes se originam e se modificam historicamente.

Segundo Zucker (1991), a institucionalização é o processo pelo qual indivíduos transmitem aquilo que é socialmente definido como real, o que corresponde a um processo de "fabricação" de verdades, de pontos de referência não mais tematizáveis. Nessa linha, uma contribuição teórica importante, embora controversa para alguns, a análise de Berger e Luckmann (2008, p. 79) procura erigir fundamentos da influência das diversas 
instituições no comportamento dos indivíduos, não obstante se possa discutir o caráter determinista dos autores. Segundo eles, "[...] a institucionalização ocorre sempre que houver uma tipificação recíproca de papéis e ações rotineiras por tipos de ator. Institucionalizar regras, por exemplo, é torná-las habituais e rotineiras". Os autores acrescentam que a institucionalização gera efeitos práticos importantes e que um valor institucionalizado é um valor que inspira ações concretas por parte dos atores sociais. Observam ainda que, embora composta por três momentos - externalização, objetivação e internalização -, é na primeira etapa que a construção desse subconsciente coletivo se origina.

A externalização é a forma como cada indivíduo interpreta suas ações, tendo-as como um sentido externo, separado deles. Ao atuar no mundo social, ao praticar um ato, pode-se observar e julgar o efeito desse ato no mundo social, de forma externa, e com isso ser capaz de avaliar o impacto dessas ações sobre os outros e também sobre o ambiente.

Quando esse debate é trazido para a análise organizacional, percebe-se que esse aspecto está presente quando ações são operacionalizadas por indivíduos que nelas interagem e as consideram como entidades abstratas, acima deles. Como decorrência, esse fenômeno acaba redundando da objetivação da realidade (ou reificação), aspecto muito bem discutido por Guerreiro Ramos (1983), que afirma que a reificação do agente social é o seu conformismo em aceitar os preceitos organizacionais sobrepostos às suas próprias convicções. Denota sentido de transformação desses indivíduos e sua intencionalidade é permitir o curso da ação administrativa pleiteada pela organização.

Essa reificação, também denominada materialização ou coisificação, para Motta e Vasconcelos (2008), significa atribuir a elementos mutáveis e contingentes, como regras, modelos sociais e cognitivos - frutos da criação humana e, portanto, modificáveis -, um caráter intangível e permanente, como se esses modelos pairassem acima de cada sujeito e tivessem de ser aceitos sem questionamento por corresponderem à "verdade". Posteriormente, essas estruturas cognitivas, regras, valores e modelos construídos e institucionalizados pelos grupos sociais são internalizados por seus membros, determinando a estrutura subjetiva de sua consciência não mais objeto de tematização.

Essa dinâmica de muitas verdades verificada nas organizações também pode ser interpretada não somente como uma das várias formas de se perceber a realidade presente nos diversos grupos, mas também como a existência de diversas racionalidades organizacionais. No cotidiano organizacional, muitas vezes, alguns desses grupos conseguem impor sua visão de mundo e suas soluções para os problemas e/ou dificuldades, entre outras possíveis, influenciando, assim, a percepção de realidade dos demais. Conforme observam Motta e Vasconcelos (2008), além do ambiente intraorganizacional, esse fenômeno também pode ser percebido, uma vez que muitas organizações influenciam-se mutuamente, estabelecendo modelos e símbolos que vão predominar em determinado contexto e que serão institucionalizados, tornando-se habituais e rotineiros.

Essas estruturas, modelos, tecnologias, padrões culturais e formas de representação da realidade predominantes em uma organização também se tornam inerentes aos setores institucionais. ${ }^{8}$ Ao serem instituídos, favorecem interesses de poder de alguns grupos, de modo que sua racionalidade predomine sobre as demais. Dessa forma, os modelos e soluções são reificados, reproduzidos e imitados, constituindo-se em padrão de comportamento e avaliação, que passa a ser seguido por outros indivíduos, grupos e organizações. De acordo com essa visão cognitivista, os mitos e modelos criados influenciam a ação dos indivíduos e das organizações que os adotam por serem fonte de legitimidade e reconhecimento, possibilitando maior capacidade de sobrevivência em certo meio.

\footnotetext{
${ }^{8}$ Para Scott e Meyer (1991) os setores institucionais são setores sociais em que predominam um conjunto de regras e normas aos quais as organizações devem se adequar, caso pretendam sobreviver e receber apoio e serem legitimadas por outras organizações, agentes econômicos, governamentais e privados.
} 
Especificamente na área da administração, Fachin e Mendonça (2003), baseados nos estudos de Selznick (1957), mostram que a coisa mais importante sobre as organizações é que, apesar delas se constituírem em agentes essencialmente instrumentais, cada uma tem vida própria que vai além do objetivado em suas estruturas. Mesmo reconhecendo o papel das organizações e que elas são constituídas para atingirem metas e gerar resultados, pode-se observar que suas estruturas formais não conseguem dominar as dimensões não racionais do seu comportamento.

\begin{abstract}
Indivíduos não agem puramente baseados nos seus papéis formais, assim como as organizações também não agem puramente baseadas em suas estruturas formais. A "institucionalização" é definida como um processo pelo qual uma organização desenvolve uma estrutura de caráter distintivo (...). (SELZNICK apud FACHIN e MENDONÇA, 2003, p. 30)
\end{abstract}

Nessa concepção, a perspectiva institucional pode ser entendida como uma abordagem simbólicointerpretativa da realidade organizacional, em que pese uma posição epistemológica onde a subjetividade predomina na construção social da realidade das organizações.

Recentemente, o termo neoinstitucionalismo ganhou destaque com as pesquisas de, Meyer e Rowan (1983), Meyer e Scott (1983) e de Zucker (1987). A nova versão da teoria institucional aponta algumas divergências que devem ser consideradas quando de seu emprego para a análise organizacional. São elas:

1. a orientação política dos adeptos do "antigo" institucionalismo, expressa na marcante ênfase no conflito de interesses na formulação da ação organizacional, pouco considerado no tratamento atual;

2. a conceitualização do ambiente, tido como componente constitutivo da organização pela nova geração, contra mero campo fornecedor de elementos de cooptação pela antiga;

3. a passagem do pensamento baseado na teoria da ação parsoniana, arraigada na abordagem freudiana do ego, para a utilização dos princípios da teoria da ação prática, originária da etnometodologia e da revolução cognitiva da psicologia. (FONSECA, 2003, p. 49)

A principal contribuição da abordagem neoinstitucional à teoria organizacional, segundo Perrow (1986), é a "ênfase na influência do ambiente, ao colocar a legitimidade e o isomorfismo como fatores vitais para a sobrevivência das organizações".

Embora alguns autores critiquem o institucionalismo por seu caráter determinista, este também pode ser analisado da perspectiva de que determinados processos de institucionalização são avaliados como vetores de mudanças organizacionais, seja pela incorporação de novas práticas, seja pela adoção de novas exigências sociais.

DiMaggio e Powell (2005), autores de referência sobre o tema na perspectiva das organizações, propõem uma tipologia sobre os processos que conduzem essas organizações a mudar estruturas e a adotar modelos cognitivos e normativos instituídos por grupos, ou outras organizações, em um dado setor. Nessa linha, as associações profissionais, corporativas e o Estado são considerados atores no processo de criação e modelagem organizacional.

O processo de inclusão desses modelos predominantes em determinado setor está inserido no fenômeno denominado isomorfismo estrutural, entendido como uma tendência das organizações de um mesmo setor possuírem estruturas, regras, modelos cognitivos e tecnologias semelhantes.

Para DiMaggio e Powell (2005), há dois tipos de isomorfismo: o isomorfismo competitivo (fruto de pressões do mercado e das relações de troca entre os integrantes de um dado espaço organizacional) e o isomorfismo 
institucional (que inclui a luta por legitimidade). Sobre o isomorfismo institucional, DiMaggio e Powell (2005, p. 77), com base em Aldrich (1979), relatam que,

[...] as principais forças que as organizações devem levar em consideração são as organizações. As organizações não competem somente por recursos e clientes, mas por poder político e legitimação institucional, por adequação social, assim como por adequação econômica.

Os modelos instituídos em um setor são adotados pela maioria, com o principal intuito de sobrevivência, tendendo à homogeneização dessas estruturas depois de certo tempo, até que outra inovação seja implantada e realimente esse ciclo.

Os processos de mudanças isomórficas ocorrem mediante três mecanismos tipificados por DiMaggio e Powell (2005, p. 77): isomorfismos coercitivo, mimético e normativo. "O isomorfismo coercitivo é aquele que deriva da influência política e do problema da legitimidade". A imposição de estruturas organizacionais e modelos podem ocorrer pela força ou pela autoridade legítima. Embora a sociedade considere que o único detentor do monopólio do uso legítimo da força ou da violência seja o Estado, é possível impor por meio da institucionalização de uma autoridade simbolicamente percebida como legítima, de modo a gerar menor resistência. Esse processo tende a ser mais estável e concretiza-se com mais rapidez do que pela imposição unicamente pela força.

O isomorfismo mimético é aquele que "resulta de respostas padronizadas à incerteza". Ocorre quando os dirigentes imitam estratégias e arranjos estruturais implantados pelos concorrentes, visando atingir o sucesso por eles conquistado, além de reduzir o risco da incerteza causada por problemas tecnológicos e objetivos conflitantes. DiMaggio e Powell, baseados em estudos de Cyert e March (1963) e de March e Olsen (1984), são convictos em afirmar que, quando as tecnologias organizacionais são insuficientemente compreendidas, quando as metas são ambíguas ou o ambiente cria uma incerteza simbólica, as organizações podem vir a tomar outras organizações como modelo.

Por fim, o isomorfismo normativo é aquele associado ao grau de profissionalização das organizações. O compartilhamento e a especialização de um conjunto de rotinas e normas de trabalho de uma determinada profissão ou ocupação possibilitam o desencadeamento do isomorfismo normativo.

A base analítica da teoria institucional permite-nos investigar os processos de homogeneização interpretativa da realidade, os quais constituem o que temos aqui denominado de subconsciente coletivo de um determinado segmento da sociedade; no caso, as organizações na esfera do mercado. Conforme será discutido adiante, esse contexto organizacional compartilhado possibilita que ações que buscam em sua origem constituir diferenciais competitivos sejam requisitadas por outras esferas da sociedade, como a pública não estatal e a própria esfera estatal, as quais conseguem institucionalizá-las, convertendo-as em um atributo de caráter qualificador. Isto é, determinadas ações ou estruturas deixam de ser uma alternativa para se constituírem numa condição de operação, seja por pressão do ambiente de mercado, seja por perderem a condição de possível tema de toda a sociedade, como é o caso de diversas ações tipificadas contemporaneamente como de responsabilidade social.

\section{A Responsabilidade Social Corporativa Sistemicamente Vinculada ao Desenvolvimento Social}

Não há dúvidas de que o tema da responsabilidade social corporativa tem ganho espaço nos últimos anos, influenciando efetivamente a concepção de estratégias empresariais específicas, as quais, por sua vez, dada 
sua potencial influência nas ações de consumo, tem suscitado um conjunto de pesquisas 9 empíricas no meio acadêmico. O senso comum midiático busca convencer a sociedade de que, efetivamente, foi alcançado um nível superior de consciência socioambiental que tem levado a ações empresariais mais parcimoniosas com relação ao ambiente material e social. Essa tese não consegue se sustentar diante de uma análise mais profunda dos movimentos de mercado. Um exemplo disso é o movimento adotado pelos grandes fundos de investimento, inclusive, aqueles denominados "éticos", que, ao primeiro dissabor em termos de rentabilidade do capital investido, alçam voos para alternativas economicamente mais rentáveis, independente dos discursos originais de uma responsabilidade socioambiental do capital. Tal movimento debilita, pela retirada de recursos, qualquer empreendimento que não consiga apresentar uma rentabilidade compatível com seu segmento de negócio, independente da nobreza de propósitos de seus gestores ou necessidades de seus stakeholders. Na mesma linha, não parece haver evidências empíricas, contundentes e massificadas, de que o consumidor esteja efetivamente disposto a onerar seu bolso com a aquisição de produtos vinculados ao selo socioambiental quando da existência de produto similar, economicamente mais atraente. ${ }^{10}$

Apesar do ceticismo dessas últimas considerações, pode-se efetivamente observar que existe um conjunto de iniciativas, enquadradas originalmente como socioambientais, que não conseguem mais serem suprimidas por ações de caráter estratégico organizacional, pois já compõem o patrimônio de exigências de atuação sobre as organizações. Pode-se afirmar que essas exigências foram institucionalizadas e passaram a compor o subconsciente coletivo da sociedade.

Diante disso, descortina-se um conjunto de possibilidades de investigação teórica que passam, inicialmente, pela análise do modo como as organizações convertem ações socioambientais em fatores de diferenciação estratégica. Na sequência, devem ser investigadas como essas iniciativas isomorficamente se generalizam no ambiente organizacional, ainda dentro da esfera do mercado. Finalmente, podem ser analisados como essas ações, estruturas e comportamentos se corporificam em padrões de racionalidade para toda a sociedade. Nesse último estágio estaria se constituindo um novo ponto de partida de ação social, incorporado sistemicamente a toda atuação organizacional.

Com relação à gênese dos fatores motivadores da ação organizacional, podem ser propostos quatro fatores que justificariam a implementação de ações socioambientais não compulsórias. ${ }^{11}$

a) a implementação de ações que gerem algum dispêndio de recursos motivado por convicções exclusivamente particulares dos gestores, não comunicadas aos stakeholders e que, não obstante sua contribuição social, não estejam previstas nos propósitos do negócio. Essa hipótese apresenta dois elementos que a excluem da análise proposta. Primeiro de tudo, por possuir um elevado potencial de gerar conflitos de agência ${ }^{12}$ e, em segundo lugar, por não se constituir um movimento social sistêmico;

b) a implementação de ações que gerem algum dispêndio de recursos, vinculado direta ou indiretamente aos propósitos do negócio, e que resultam em um diferencial competitivo no produto ou serviço na perspectiva do consumidor. Essas iniciativas apresentam características estratégico-competitivas que podem aliar resultado econômico e benefício socioambiental, a exemplo da utilização de saches de reposição para cosméticos e embalagens retornáveis, entre outros;

\footnotetext{
${ }^{9}$ Ashley (2005); Bhattacharya e Sen (2004); Kreitlon (2004); Machado Filho (2010); Magalhães e Damacena (2007); Schommer e Rocha (2007); Serpa e Avila (2006).

${ }^{10}$ Ressalvadas aquelas situações onde a inobservância é evidente e constrangedora.

${ }^{11}$ Não serão consideradas na análise as alternativas de caráter legal e compulsórias.

${ }^{12}$ Neste aspecto veja Jensen e Meckling (2008).
} 
c) a implementação de ações que gerem algum dispêndio de recursos não vinculados aos propósitos do negócio, mas que tenham um efeito positivo na reputação da empresa e sua marca. Essas iniciativas apresentam como principal característica a conquista de uma legitimidade social pela organização como um todo, independente de uma linha específica de produto. Um exemplo de ação com tais características são os programas de segurança no trânsito promovidos por uma universidade;

d) a implementação de ações que gerem algum dispêndio de recursos e que estão indiretamente vinculadas aos propósitos do negócio, objetivando reduzir o grau de vulnerabilidade legal ou exposição da imagem da empresa em função de sua atividade. Um exemplo típico dessas iniciativas são programas de preservação ambiental, patrocinados por empresas de exploração de combustível fóssil, como o projeto Taim da Petrobras.

O caráter formal do estabelecimento de novos padrões de operação das organizações, utilizando o conceito de responsabilidade definido neste artigo, ocorre somente em uma situação, qual seja, quando ocorre a normatização social de um determinado procedimento que passa a ser contingenciado. Porém, nesse aspecto, o agente indutor da mudança não é a organização, mas o poder social instituidor que, independente dos fatores que o motivam, estabelece um novo "ponto mínimo de operação". A partir desse ponto, para exemplificar, toda evolução da legislação ambiental que se insere nessa situação perde seu caráter estratégico competitivo na perspectiva do mercado, tornando-se uma questão de direito, regulado pela esfera estatal, visto que o cumprimento legal não se caracteriza como um elemento distintivo ante o mercado.

É evidente que esse quadro traz consigo todo um potencial de investigação dos fatores que levam a sociedade a modificar normativamente a atuação organizacional, estabelecendo novos pontos de partida para as organizações.

Figura 1

\section{Processo de institucionalização das ações sociais de caráter estratégico}

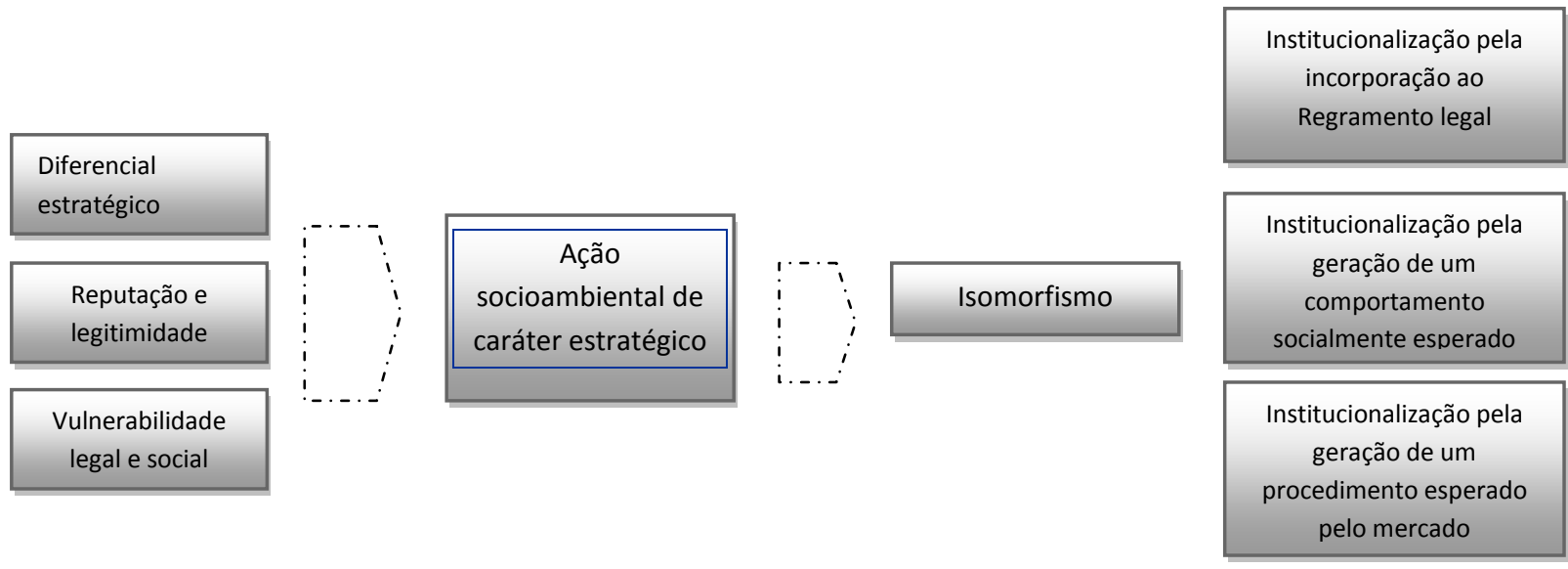

Fonte: elaborada pelos autores.

A dinâmica aqui proposta e retratada na figura 1 considera que, independente das motivações iniciais das organizações (diferencial estratégico, reputação ou redução da vulnerabilidade), algumas iniciativas seguem uma trajetória rumo à institucionalização decorrente de um aprimoramento na formação dos juízos morais de toda a sociedade, que passa a valorizar esse tema, mesmo que ainda em caráter individual, na esfera privada. Somente quando se analisa a interação do tema nas esferas pública e do mercado é possível realmente atribuir um caráter sistêmico ao tema e organizar desdobramentos da pesquisa empírica. 
No que concerne à diferenciação, para exemplificar, pode-se mencionar todo o conjunto de iniciativas que possuam algum vínculo com o produto ou serviço de uma determinada organização e que pelo seu modo de produção, entrega ou consumo distinguem-se positivamente em um determinado mercado a partir de novos elementos simbólicos valorizados por esse estrato social. Dessa forma, o desafio das organizações é justamente acompanhar a evolução sociocultural de sua comunidade de referência, para identificar oportunidades de vinculação de seu produto/serviço a esse comportamento esperado.

Uma iniciativa adequada a essas características é o fornecimento de produtos sob a modalidade de refil de reposição, iniciativa que reduz a produção de materiais sintéticos poluentes e que também reduz o volume de lixo produzido pelo consumidor. Essa é uma iniciativa ainda não regulamentada legalmente, vinculada a um produto objetivo, passível de valorização social e, por consequência, de geração de movimento econômico positivo para a organização proponente.

A segunda possibilidade de enquadramento estratégico de uma iniciativa socioambiental apresentado na figura 1 vincula-se a seu caráter de legitimação social, ou seja, de gerar uma percepção positiva, não de um produto, mas da marca como um todo. Diferente da abordagem anterior, nesta admitem-se ações que fujam ao negócio propriamente dito, desde que comunicadas à sociedade e com potencial de vinculação à marca, à reputação da organização. Exemplo disto são as iniciativas de crédito consciente e de planejamento financeiro das instituições financeiras, os programas de segurança no trânsito promovidos por instituições de ensino ou ainda o apoio sistemático a instituições de assistência como as Apaes.

Independentemente de adotar-se uma abordagem de diferenciação ou de legitimação social, ambas as iniciativas têm um amplo potencial de contribuir para o negócio principal, pois agem em elementos simbólicos amplamente valorizados na sociedade contemporânea, principalmente, pelas gerações mais jovens. O desafio empresarial é identificar o tipo de iniciativa concreta que melhor se vincule a esses elementos simbólicos.

Identificada essa vinculação e validada pelo mercado de um determinado setor, o que é externado como uma postura socialmente responsável é, na verdade, uma ação social estratégica e que, desse modo, deverá ser analisada na teoria organizacional. É justamente nesse ponto que inicia toda a dinâmica de isomorfismo que ao final de seu ciclo terá convertido essa ação inicialmente estratégica, numa postura qualificadora de um determinado segmento, estabelecendo assim um novo ponto de partida na arena competitiva do segmento.

Como retratado na figura 2, a seguir, existe um vácuo institucional que vai desde a identificação de uma oportunidade de diferenciação por uma organização até o momento em que essa iniciativa é socialmente institucionalizada. Nessa fase, as ações obedecem à dinâmica dos mercados competitivos pela qual podem ser ignoradas, levando a que sejam descartadas ou, seguindo o processo de isomorfismo, vão, pouco a pouco, perdendo seu caráter de diferenciação, mas fortalecendo seu papel na lógica do desenvolvimento da sociedade. 


\section{Figura 2}

\section{Processo de institucionalização das ações sociais na lógica do desenvolvimento}

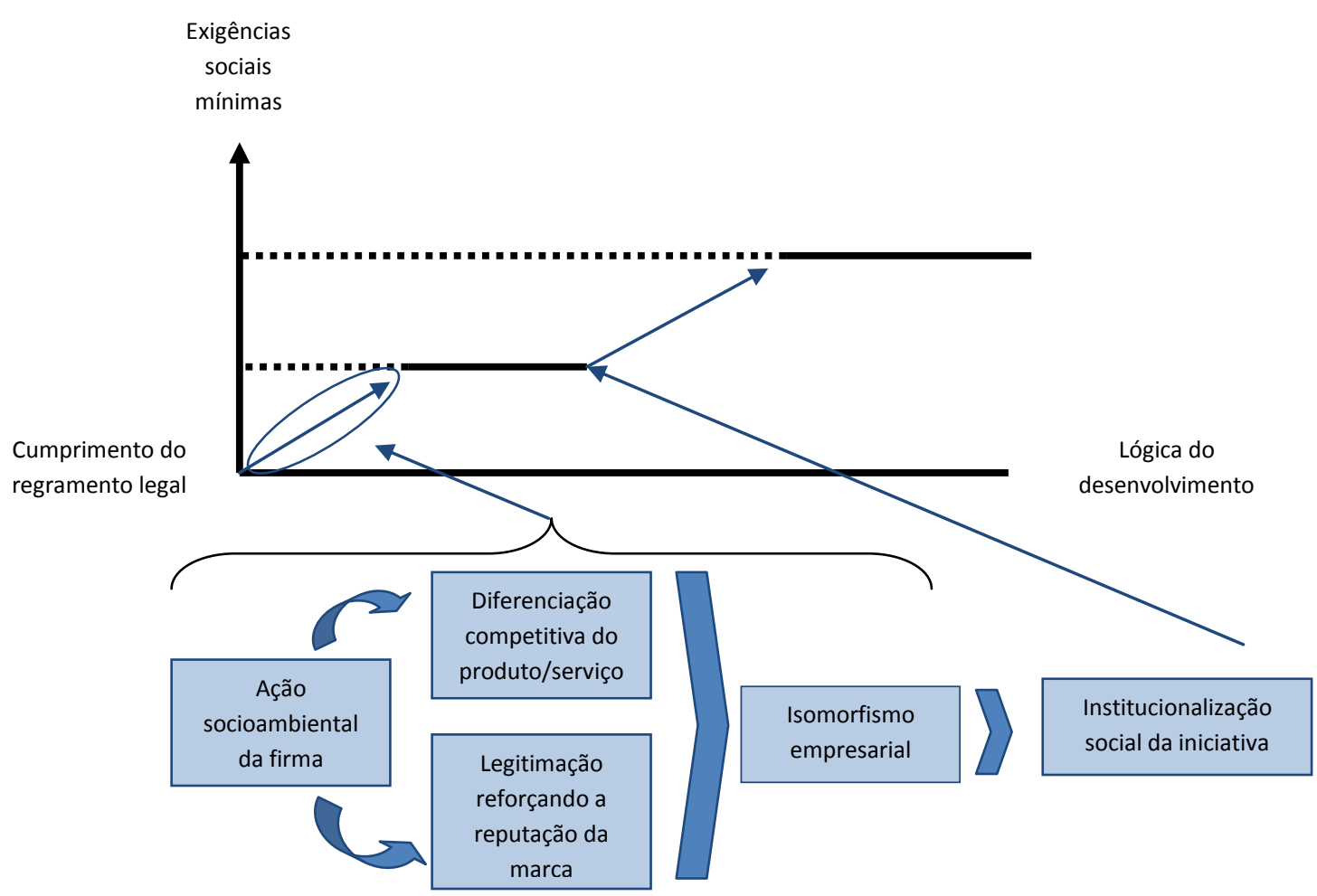

Fonte: elaborada pelos autores.

Nesta perspectiva, a análise do tema relega a um plano não central, embora relevante, as concepções morais individuais de um determinado gestor para tomá-lo sistemicamente dentro das próprias regras e dinâmicas da sociedade em suas quatro esferas: individual, de mercado, estatal e pública não estatal. Dessa perspectiva seria possível gerenciar, prospectar e analisar os avanços socioambientais na dimensão organizacional, no contexto de uma lógica de desenvolvimento, como a preconizada por Habermas. Isto é, o fechamento de um ciclo isomórfico na arena socioambiental estabelece um novo ponto de partida, que é institucionalizado e passa a ser exigido socialmente, compondo o subconsciente coletivo e o patrimônio de exigências mínimas de atuação organizacional construído pela sociedade.

\section{Considerações finais}

O entendimento do estudo do processo de institucionalização ou da materialização da responsabilidade social e como esse tema passa a interferir nas concepções de realidade dos sujeitos e das organizações é amplo e desafiador. Os diferentes níveis de análise sobre os processos de institucionalização enriquecem a compreensão a respeito da dinâmica de transformação dos fenômenos organizacionais. A partir da linha de pensamento da lógica de desenvolvimento de Habermas e da teoria institucional, entende-se que seja possível sistematizar o tema em termos de uma análise socioeconômica organizacional. As premissas de ambas as teorias permitem analisar as iniciativas das organizações nessa área, seja no sentido de buscarem 
sua sustentabilidade, seja procurando garantir níveis mínimos de legitimidade nas comunidades em que interagem.

A tematização priorizou o entendimento pelo viés da competição, julgando-se que o que é externado como uma postura socialmente responsável (de caráter socioambiental) pode ser compreendido sistematicamente como uma ação social estratégica, que, desse modo, pode ser analisada segundo a teoria organizacional. Dessa forma, considera-se que as estratégias têm um princípio claramente econômico e competitivo, voltadas para a busca de melhores níveis de posicionamento, seja como fator de diferenciação, seja como elemento legitimador junto ao mercado. Nesse ponto, é proposta a investigação do tema da perspectiva do isomorfismo que, ao final de seu ciclo, terá convertido essa ação - que inicialmente era considerada estratégica - em uma postura "habilitadora" de um determinado segmento, estabelecendo assim um novo ponto de partida na arena competitiva do segmento e, por decorrência, também na sociedade.

Portanto, à medida que as ações de responsabilidade socioambientais assumidas por uma empresa tornam-se recorrentes, o nível de aprendizado e amadurecimento das organizações e da própria sociedade aumenta, pois ao institucionalizar um conjunto de elementos, vai gradativamente determinando comportamentos para outras organizações que, por sua vez, também podem dar origem a comportamentos ou procedimentos que passarão por processos de institucionalização.

Esse enfoque de investigação da atuação das empresas na arena socioambiental rompe com a perspectiva ingênua e voluntarista de que a emergência dessas iniciativas ocorra em função de diferentes níveis de conscientização do meio empresarial. Não se ignora aqui a relevância da formação de juízos morais como fator decisivo nesse comportamento, mas seu entendimento é potencializado se o analisarmos de modo sistêmico, dentro da lógica do processo competitivo e de desenvolvimento da sociedade como um todo.

Por fim, resta dizer que com esse construto teórico pretendeu-se explicar como acontece o processo de institucionalização das ações sociais de caráter estratégico, a partir da proposição de um modelo teórico que estabelece interfaces entre a teoria do desenvolvimento social de Habermas e o isomorfismo da teoria institucional. Por se tratar de um ensaio teórico, fica a proposição de futuras pesquisas teórico-empíricas, procurando validar o modelo proposto. 


\section{Referências}

ABBAGnANO, N. Dicionário de filosofia. São Paulo: Martins Fontes, 2000.

ALDRICH, H. E. Organizations and Environments. Englewood Cliffs, NJ: Prentice Hall, 1979.

ARAGÃO, L. M. de C. Razão comunicativa e teoria social crítica em Jurgen Habermas. Rio de Janeiro: Tempo Brasileiro, 1992.

ASHLEY, P. A. et al. Ética e responsabilidade social nos negócios. São Paulo: Saraiva, 2005.

BERGER, P. L.; LUCKMANN, T. A construção social da realidade: tratado de sociologia do conhecimento. 29. ed. Tradução de Floriano de Souza Fernandes. Petrópolis: Vozes, 2008.

BHATTACHARYA, C. B.; SEN, S. Doing better at doing at good: when, why, and how consumers respond to corporate social initiatives. Management Review, California v. 47, n. 1, p. 9-24, 2004.

BOBBIO, N. A era dos direitos. Rio de Janeiro: Saraiva, 1992.

CYERT, R.; MARCH, J. A Behavioral Theory of the Firm. Englewood Cliffs, NJ: Prentice-Hall, 1963.

DIMAGGIO, P. J.; POWELL, W. W. A gaiola de ferro revisitada: isomorfismo institucional e racionalidade coletiva nos campos organizacionais. RAE-CLÁSSICOS, v. 45. n. 2, abr./jun. 2005.

FACHIN, R. C.; MENDONÇA, R. C. Seznick: uma visão da vida e da obra do precursor da perspectiva institucional na teoria organizacional. In: VIEIRA, M. M. F.; CARVALHO, C. A. (Org.). Organizações, instituições e poder no Brasil. Rio de Janeiro: FGV, 2003.

FONSECA, V. S. A abordagem institucional nos estudos organizacionais: bases conceituais e desenvolvimentos contemporâneos. In: VIEIRA, M. M. F.; CARVALHO, C. A. (Org.). Organizações, instituições e poder no Brasil. Rio de Janeiro: FGV, 2003.

GUERREIRO RAMOS, A. Administração e contexto brasileiro: esboço de uma teoria geral da administração. 2. ed. Rio de Janeiro: FGV, 1983.

HABERMAS, J. Consciência moral e agir comunicativo. Tradução: Guido Antônio de Almeida. Rio de Janeiro: Tempo Brasileiro, 1989.

HALL, P.; TAYLOR, R. As três versões do neoinstitucionalismo. Lua Nova, São Paulo, n. 58, p. 193-223, 2003.

JENSEN, M. C.; MECKLING, W. H. Teoria da firma: comportamento dos administradores, custos de agência e estrutura de propriedade. Revista de Administração de Empresas, v. 48, n. 2, p. 87-125, Abr./Jun. 2008.

KOHLBERG, L. The Development of Modes of Thinking and Choices in Years 10 to 16. Ph. D. Dissertation, University of Chicago, 1958.

KREITLON, M. P. A ética nas relações entre empresas e sociedade: fundamentos teóricos da responsabilidade social empresarial. In: ENCONTRO DA ASSOCIAÇÃO NACIONAL DE PÓS-GRADUAÇÃO E PESQUJISA EM ADMINISTRAÇÃO - ENANPAD, 28., 2004, Curitiba. Anais... Curitiba: ANPAD, 2004. 
MACHADO FILHO, C. A. P. Governança e responsabilidade social corporativa. Disponível em: <http://www.tiespecialistas.com.br/2010/11/governanca-e-responsabilidade-social-corporativa-rsc/>. Acesso em: 18 nov. 2010.

MAGALHÃES, J. M.; DAMACENA, C. Estudo dos efeitos da responsabilidade social corporativa e do envolvimento sobre o comportamento do consumidor. In: ENCONTRO DA ASSOCIAÇÃO NACIONAL DE PÓS-GRADUAÇÃO E PESQUISA EM ADMINISTRAÇÃO - ENANPAD, 31., 2007, Rio de Janeiro. Anais... Rio de Janeiro: ANPAD, 2007.

MARCH, J. G.; OLSEN, J. P. The New Institutionalism: Organizational Factors in Political Life. The American Political Science Review. v.78, n. 3, p.734-749, Set. 1984.

MEYER, J. W.; ROWAN, B. The Structure of Educational Organizations. In: MEYER, J. W.; SCOTT, W. R. (Eds.). Organizational environment: ritual and rationality. Beverly Hills, CA: Sage, 1983. p. 199-215.

; SCOTT, W. R. Organizational Environments: Ritual and Rationality. Beverly Hills, CA: Sage, 1983.

MOTTA, F. C. P.; VASCONCELOS, I. F. G. Teoria geral da administração. 3. ed. São Paulo: Cengage Learning, 2008 .

PERROW, C. Complex organizations: a critical essay. New York: McGraw-Hill, 1986.

SCHOMMER, P. C.; ROCHA, F. C. C. As três ondas da gestão socialmente responsável no Brasil: dilemas, oportunidades e limites. In: ENCONTRO DA ASSOCIAÇÃO NACIONAL DE PÓS-GRADUAÇÃO E PESQUJISA EM ADMINISTRAÇÃO - ENANPAD, 31., 2007, Rio de Janeiro. Anais... Rio de Janeiro: ENANPAD, 2007.

SCOTT, W. R.; MEYER, J. W. The organization of societal sectors. In: DIMAGGIO, P. J.; POWELL, W. W. The new institutionalism in organizational analysis. Chicago: The University of Chicago Press, 1991.

SELZNICK, P. Leadership in administration: a sociological interpretation. Berkeley and Los Angeles: University of California Press, 1957.

SERPA, D. A. F.; AVILA, M. Efeitos da responsabilidade social corporativa na percepção do consumidor sobre preço e valor: um estudo experimental. In: ENCONTRO DA ASSOCIAÇÃO NACIONAL DE PÓS-GRADUAÇÃO E PESQUJISA EM ADMINISTRAÇÃO - ENANPAD, 30., 2006, Salvador. Anais... Salvador: ENANPAD, 2006.

VIEIRA, L. Os argonautas da cidadania. Rio de Janeiro. Record, 2001.

ZUCKER, L. G. Institutional theories of organization. Annual Review of Sociology, v. 13, p. 443-464, 1987.

The role of institutionalization in cultural persistence. In: DiMAGGIO, P. J.; POWELL, W. W. (Edit.). The new institutionalism in organizational analysis. Chicago: The University of Chicago Press, 1991. 83-107 p. 